\title{
A TECHNIQUE FOR ELECTRO-EJACULATION IN CHINCHILLAS
}

\author{
P. HEALEY AND BARBARA J. WEIR \\ Wellcome Institute of Comparative Physiology, Zoological Society of London, \\ Regent's Park, London
}

(Received 28th December 1966)

This technique was standardized on chinchilla (Chinchilla laniger) as part of two wider projects: (a) to investigate a method for artificial insemination (Weir, 1966), and (b) an electron microscope study of the spermatozoa.

Dalziel \& Phillips (1948) used unipolar lumbar-anal electrodes on both guinea-pigs and chinchillas, Scott \& Dziuk (1959) reported success with bipolar rectal electrodes on rats, mice and guinea-pigs. Hillemann, Gaynor \& Dorsch (1963) described an electro-ejaculation method in chinchilla, but gave no details of the electrode or of the voltage used (Table 1).

Some of the sixty-four chinchillas used were those already in our colony and the rest were kindly lent by two chinchilla ranchers. The electrode was a multiring type (Healey \& Sadleir, 1966) $12 \mathrm{~cm}$ long $\times 6.5 \mathrm{~mm}$ in diameter with 2.5 $\mathrm{mm}$ brass rings separated by $4.5 \mathrm{~mm}$ wide Araldite (Ciba A.R.L. Ltd, Duxford, Cambridgeshire) coated brass collars. Each ring was connected to a multiple socket but only the terminal two rings were used throughout, the remaining rings serving as a gauge indicating the distance that the pole was inserted into the rectum. The current was supplied by an electronic squarewave stimulator (G. F. Palmer Ltd, London, Type Model H.45) providing chopped direct current at a fixed pulse width of $5 \mathrm{msec}$ and a frequency of 64 cyc/sec. The voltage was set at 8.0 or $9.5 \mathrm{~V}$ as indicated below. The current was calculated from an oscilloscope reading of the voltage drop across a resistor placed in the circuit, and proved to be $5.0 \mathrm{~mA}$ at the lower setting rising to $5.5 \mathrm{~mA}$ at the higher voltage.

The unanaesthetized chinchilla was restrained on its back by a leather strap over the neck and a canvas strap over the thorax. The rectal pole was lubricated with soap solution and inserted into the rectum to a depth of $32 \mathrm{~mm}$, after all faecal pellets had been removed. This is a difficult position to maintain throughout, especially during the initial shocks, because the chinchilla pushes very hard to expel the pole. Movement of the pole was minimized by holding it firmly to the tail base. The current was applied for $4 \mathrm{sec}$ out of every $10 \mathrm{sec}$. A series of ten shocks was normally given at the $8.0 \mathrm{~V}$ setting and, if ejaculation had not then occurred, a further five shocks at $9.5 \mathrm{~V}$ were applied. The ejaculation attempt was abandoned after fifteen shocks if no response was obtained as most of the animals used were unaccustomed to the treatment and it was desirable to avoid undue stress. 


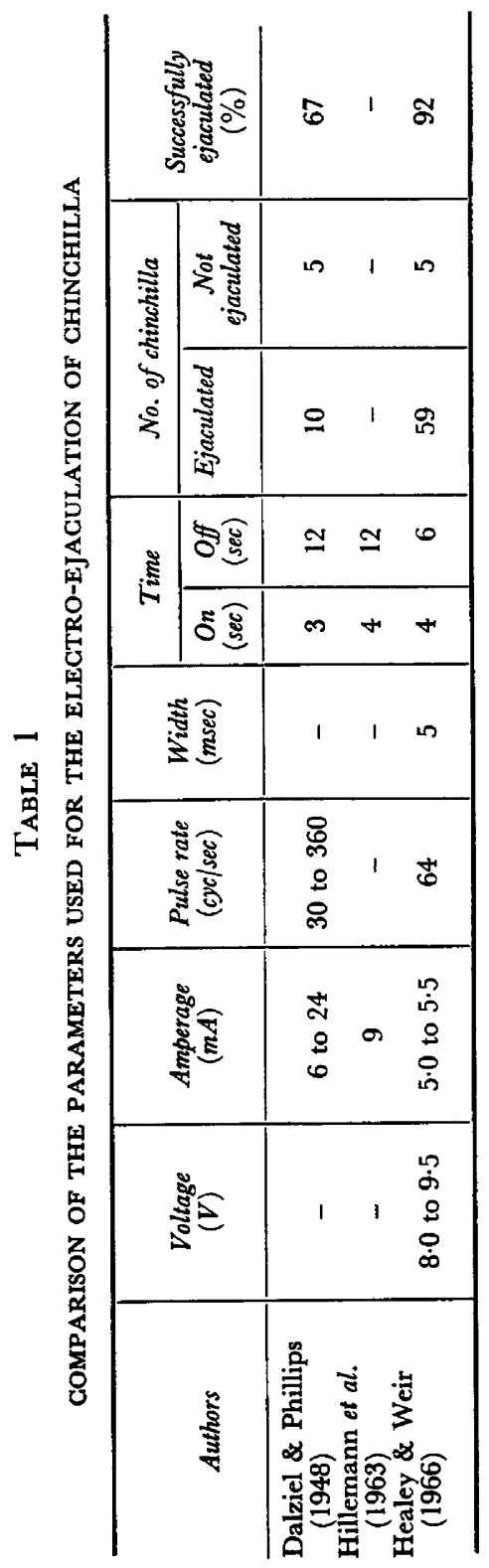


The effect on the animals was very specific; in no instance was urine seen at the urethral orifice and on several occasions an almost complete copulatory pattern of forward erection of the penis, pelvic thrusting and ejaculation was seen. Most of the animals responded with some tumescence of the base of the penis and an ejaculate which oozed from the urethral aperture. The form of the ejaculate varied from a coagulum-free seminal emission through a coagulating material containing spermatozoa to a sperm-free, but non-coagulating, fluid. Coagulation of the accessory secretions made accurate measurement of ejaculation volume very difficult but measured volumes varied between 0.01 and $0.07 \mathrm{ml}$. In one laboratory male which had been vesiculectomized, the volume of the non-coagulating ejaculate was $0.03 \mathrm{ml}$. None of the animals was ejaculated more than once a week and at this interval no change in the degree of coagulation was observed (Freund, 1958). There were no deaths and only five failures to ejaculate. In these five there were signs of partial erection and a higher voltage or longer series of shocks might have been more successful.

There appeared to be two possible explanations for the production of spermfree ejaculates. One was that the animals were immature and therefore had no spermatozoa in the epididymis, and the other that only the prostate was being stimulated. The former was found to be the case after laparotomy in one laboratory male, but this course of determination was not possible for the other examples and some of them were already proven sires, so we assume that these were cases of prostatic excitation. To investigate the anatomical relations of the electrode within the animal a chinchilla was killed and the position of the rectal pole observed. The terminal ring of the electrode was found to be near the colliculus. Thus any slight anatomical variations between animals, together with the elimination attempts already described, would be enough to prevent the electrode tip penetrating past the prostatic region. In future trials this will be tested by inserting the electrode further.

This technique is preferred to that of Dalziel \& Phillips (1948) as our larger sample, given far fewer and smaller shocks, proved more successful (see Table 1). Furthermore, the method of Dalziel and Phillips cannot be repeated since the voltages used on chinchilla do not appear to have been measured.

The efficacy of our electrode and electronic arrangement was tested using related species of hystricomorph rodent. The mountain viscacha (Lagidium peruanum), the chinchilla's closest relative, showed slight indications of penial tumescence and at an $11.0 \mathrm{~V}$ setting a behavioural reaction similar to that of chinchilla, but there was no ejaculation, possibly because of the immaturity of the animal. The technique had no effect on guinea-pigs. For both the agouti (Dasyprocta agouti) and the acouchi (Myoprocta pratti) under Fluothane (I.C.I.) anaesthesia, erection was seen but no ejaculation achieved. It was not considered that the anaesthetic prevented a response in these species since the technique works equally well in the Fluothane or Nembutal (Abbott) anaesthetized chinchilla; and our conclusion is that this method of electroejaculation is specific for chinchilla and that small modifications of the electrode and of the shock pattern given might be successful for other species.

We are indebted to Mrs U. Mainwaring and Mr J. Rendell for their kindness 
in lending us males from their ranches, to $\mathrm{Dr} H$. Dott for reading the manuscript, and to the Ford Foundation for grants to Professor A. S. Parkes and Dr I. W. Rowlands which enabled the laboratory chinchilla to be purchased and maintained and for a personal studentship to one of us (B.J.W.).

\section{REFERENCES}

Dalziel, C. F. \& Phillips, C. L. (1948) Electric ejaculation. Determination of optimum electric shock to produce ejaculation in chinchillas and guinea-pigs. Am. 7. vet. Res. 9, 225.

FreUnd, M. (1958) Collection and liquefaction of guinea-pig semen. Proc. Soc. exp. Biol. Med. 98, 538.

HeAley, P. \& SADLEIR, R. M. F. S. (1966) The construction of rectal electrodes for electro-ejaculation. 7. Reprod. Fert. 11, 299.

Hillemann, H. H., Gaynor, A. I. \& Dorsch, A. (1963) Artificial insemination in chinchillas. F. small Anim. Pract. 3, 77.

Scotт, J. V. \& Dziuk, P. J. (1959) Evaluation of the electro-ejaculation technique and the spermatozoa thus obtained from rats, mice and guinea-pigs. Anat. Rec. 133, 655.

WEIR, B. J. (1966) Aspects of reproduction in chinchilla. J. Reprod. Fert. 12, 410. 